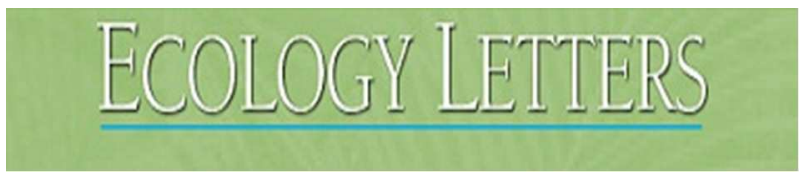

\title{
Migratory diversity predicts population declines in birds
}

\begin{tabular}{|r|l|}
\hline Journal: & Ecology Letters \\
\hline Manuscript ID & ELE-00934-2015.R1 \\
\hline Manuscript Type: & Letters \\
\hline Date Submitted by the Author: & n/a \\
\hline Complete List of Authors: & $\begin{array}{l}\text { Gilroy, James; University of East Anglia, School of Environmental Science } \\
\text { Gill, Jennifer; University of East Anglia, School of Biological Sciences } \\
\text { Butchart, Stuart; Birdlife International, } \\
\text { Jones, Victoria; Birdlife International, } \\
\text { Franco, Aldina; University of East Anglia, Environmental Sciences }\end{array}$ \\
\hline Key Words: & $\begin{array}{l}\text { Migratory strategy, partial migration, population trends, climate change, } \\
\text { behavioural plasticity, European birds, Afrotropical migrants }\end{array}$ \\
\hline
\end{tabular}



Migratory diversity predicts population declines in birds

\section{James J. Gilroy ${ }^{a^{*}}$, Jennifer A. Gill ${ }^{\text {b }}$, Stuart H. M. Butchart ${ }^{\mathfrak{c}}$, Victoria R. Jones ${ }^{\mathrm{c}}$ \& Aldina}

3 M. A. Franco ${ }^{\mathbf{a}}$

$4 \quad$ a School of Environmental Science, University of East Anglia, Norwich Research Park,

$5 \quad$ Norwich NR4 7TJ, UK

$6 \quad{ }^{\mathrm{b}}$ School of Biological Science, University of East Anglia, Norwich Research Park, Norwich

$7 \quad$ NR4 7TJ, UK

$8 \quad{ }^{\mathrm{c}}$ BirdLife International, Wellbrook Court, Cambridge CB30NA, UK

9 Running title: Migratory diversity and population trends

10 Keywords: Migratory strategy, partial migration, population trends, climate change,

11 behavioural plasticity, European birds, Afrotropical migrants

12 Type of article: Letter

13 Abstract words: 152; Main text words: 4235; References: 51; Figures: 5; Tables: 1; Boxes: 0

14 *Correspondence to: James J. Gilroy, School of Environmental Science, University of East

15 Anglia, Norwich Research Park, Norwich NR4 7TJ, UK, Tel: +44 (0)1603 592543 Fax: +44

$16 \quad(0) 1603591327$

17 Author contributions: JJG, JAG \& AMAF conceived the study, SHMB \& VRJ provided data,

$18 \mathrm{JJG}$ performed the analyses and wrote the first draft, all authors contributed significantly to 19 revisions. 


\begin{abstract}
23 Abstract
24 Declines in migratory species are a pressing concern worldwide, but the mechanisms

25 underpinning these declines are not fully understood. We hypothesised that species with

26 greater within-population variability in migratory movements and destinations, here termed

27 'migratory diversity', might be more resilient to environmental change. To test this, we

28 related map-based metrics of migratory diversity to recent population trends for 340

29 European breeding birds. Species that occupy larger non-breeding ranges relative to breeding,

30 a characteristic we term 'migratory dispersion', were less likely to be declining than those

31 with more restricted non-breeding ranges. Species with partial migration strategies (i.e.

32 overlapping breeding and non-breeding ranges) were also less likely to be declining than full

33 migrants or full residents, an effect that was independent of migration distance. Recent rates

34 of advancement in Europe-wide spring arrival date were greater for partial migrants than full

35 migrants, suggesting that migratory diversity may also help facilitate species responses to

36 climate change.
\end{abstract}


39

40

41

42

\section{Introduction}

A wide range of migratory birds, mammals, fish and invertebrates have shown population declines in recent decades (Wilcove \& Wikelski 2008), with causes linked to climate change (Both et al. 2006; Møller et al. 2008) and habitat loss (Robbins et al. 1989; Sanderson et al. 2006; Berger et al. 2008) among other factors. Migrants can experience 'multiple jeopardy' owing to their reliance on different sites across the annual cycle, potentially increasing their risk of exposure to spatially-heterogeneous threats (Wilcove \& Wikelski 2008; Vickery et al. 2014). Importantly, declines have not been uniform across migratory species (Sanderson et al. 2006; Thaxter et al. 2010; Vickery et al. 2014), implying that some traits associated with migration might confer particular sensitivity to environmental change. Identifying these traits could help us determine which species are at greatest risk of continuing decline.

Some lines of evidence suggest that the magnitude of migratory movements made by species can influence their vulnerability to environmental change (Wilcove \& Wikelski 2008). Among birds, for example, long-distance migrants have shown steeper declines than residents and short-distance migrants (Sanderson et al. 2006; Morrison et al. 2013). However, such simple classifications of migration distance obscure a complex spectrum of withinspecies variation in migratory movements. Often, for example, populations comprise a mixture of individuals that migrate longer and shorter distances, or vary significantly in migration direction (Chapman et al. 2011a; Vardanis et al. 2011). This diversity of migratory movement determines the spatial distribution of the population during the non-breeding season, which in turn has important implications for population dynamics (Sutherland \& Dolman 1994, Runge et al. 2014).

By expressing a diverse range of migratory movements, some populations are able to spread widely across many sites during the non-breeding period (Fig. 1A). In others, 
63 migratory movements cause populations to converge within smaller non-breeding areas (Fig.

64 1B). We hypothesize that this characteristic, which we term 'migratory dispersion', could

65 play an important role in determining the resilience of populations to environmental change.

66 In a simple network model of a migratory population (Appendix S1), networks with low

67 migratory dispersion show greater declines following non-breeding habitat loss than those

68 with high dispersion (Fig 2A-D). Indeed, these models predict that migratory dispersion can

69 have a greater influence on population resilience than the allied phenomenon of "migratory

connectivity' (Fig. S1), which relates to the intermixing of individuals from different

breeding sites within non-breeding sites (Webster et al. 2002). Despite considerable interest

72 in the implications of migratory connectivity (e.g. Taylor \& Norris 2010; Betini et al. 2015),

73 the importance of migratory dispersion has received little attention.

In some species, the expression of migratory behaviour itself varies between

75 individuals, such that populations contain both residents and migrants (Lundberg 1988).

76 Such 'partial migration' has been observed widely across both marine and terrestrial biomes,

77 and in a wide range of taxonomic groups (including invertebrates, fish, birds and mammals;

78 Chapman et al. 2011b). However, it is unclear whether this component of migratory diversity

79 also influences of the resilience of populations to environmental change (Chapman et al.

80 2011b). Network models again suggest that partially migratory populations may be more

81 resilient to changes such as habitat loss than fully migratory populations, if those changes

82 occur in non-breeding sites (Fig. 2C).

Here, we examine the link between migratory diversity and population resilience

using data on recent trends for 340 European breeding bird species. Despite rapid

85 improvements in individual tracking technology, we still lack the capacity to quantify

86 between-individual variation in migratory movements for the majority of these species. We

87 can, however, draw inferences about their migratory diversity using map-based metrics of 
seasonal change in species distributions. We use these to test whether migratory dispersion

89 (measured as the relative difference in size between breeding and non-breeding ranges) and

partial migration strategies (measured as partial overlap between breeding and non-breeding ranges) influence the probability that species have declined over recent decades, controlling for other species traits and climatic niche characteristics.

We also hypothesize that migratory diversity might be linked to changes in mean spring arrival date are closely correlated with recent population trends in some European migratory birds, with declines being more severe among species that have failed to advance their mean arrival dates (Møller et al. 2008). A link between arrival advancement and migratory diversity could arise if species with diverse migratory strategies also show greater variation in the timing of movement (López-López et al. 2014). To examine this, we assess the correlation between migratory diversity metrics with interspecific variation in the advancement of mean spring arrival, and assess whether arrival advancement and migratory diversity play complementary roles in explaining species population trends. These analyses help us pinpoint species traits associated with resilience to anthropogenic change, with 104 potential utility in assessments of species vulnerability.

\section{Methods}

\section{Population trend and distribution data}

107 We used data compiled from country-specific monitoring programs for two periods: a 19901082000 census compiled in Birds in Europe (BirdLife International 2004) and a 2001-2012 109 census compiled in the European Red List of Birds (BirdLife International 2015). For each 110 census period, we used the trend estimates to class each species as either declining, stable, 111 increasing or fluctuating in population size across Europe. 
112 To quantify the breeding and non-breeding ranges of each species, we used current

113 distribution maps (BirdLife International and NatureServe 2014) constrained to Eurasia west

114 of $52^{\circ} \mathrm{E}$ for breeding and Africa and Eurasia west of $52^{\circ} \mathrm{E}$ for non-breeding (excluding areas

115 occupied only during passage). In subsequent analyses, we excluded any species whose

116 European breeding populations migrate primarily to areas outside the study area (e.g. in

117 Asia), as well as those with non-breeding populations in Europe or Africa that originate from

118 outside the study area (Table S1). We also excluded fully-pelagic species, and species that

119 breed extensively within sub-Saharan Africa, leaving 340 species for analysis (Table S1).

\section{Metrics of migratory diversity}

121 We used two metrics to describe migratory diversity (Fig. 1). To measure migratory

122 dispersion (i.e. the extent to which species inhabit larger or smaller areas in the non-breeding

123 season, relative to breeding range size), we calculated the following index:

$$
\text { Dispersion }=\frac{\log _{10}\left(A_{\text {nonbreeding }}\right)-\log _{10}\left(A_{\text {breeding }}\right)}{\log _{10}\left(A_{\text {breeding }}\right)}
$$

where $A_{\text {nonbreeding }}$ and $A_{\text {breeding }}$ are the sizes of the two seasonal ranges, log-transformed

to attain normality. The denominator controls for the expected positive relationship between

breeding range size and diversity in migratory movements. To quantify partial migration, we

classified each species according to migratory strategy ('full resident', 'partial migrant' or

'full migrant') using season-specific range maps. Although partial migration has been defined

129 in many ways (see Chapman et al. 2011b), it usually refers the co-occurrence of migratory

130 and non-migratory phenotypes within a population. Given the paucity of information on

131 individual-level phenotypic variation across species, we classified migratory strategy simply

132 according to the presence of overlap between breeding and non-breeding ranges: full

133 migrants have zero overlap, residents have complete overlap, and partial migrants have 
134 overlap greater than zero and less than one. As such, both our partial migrant and resident

135 classes could include some species with 'stepping stone' or 'chain' migration patterns that

136 might result in seasonal range overlap despite a lack of fully resident phenotypes (Nilsson et

137 al. 2008). Of the 340 species considered, we classified $49.7 \%$ as partial migrants, $33.8 \%$ as

138 full migrants and $16.5 \%$ as full residents.

139 Other predictors of population trends

140 We also hypothesized that species occupying a broader range of climatic conditions may be

141 more resilient to environmental variability, and hence anthropogenic impacts. We modelled

142 the breadth of species' climatic niches during breeding and non-breeding periods, and

143 measuring between-season niche conservatism, using methods adapted from Broennimann et

144 al. (2012). First, we converted species range polygons into point grids using a $0.25^{\circ}$

145 resolution. We then selected eight biologically-meaningful climate variables from the bioclim

146 database (see Table S2; Hijmans et al. 2005) to develop multivariate PCA axes characterising

147 climate variation across each species' seasonal range (breeding=April-July, non-

148 breeding=Nov-Feb) during the whole survey period (1990-2012). Axes were constrained

149 within the seasonal maxima and minima of each variable, and calibrated on the full

150 environmental space (Broennimann et al. 2012). We calculated an index of climate niche

151 breadth by summing niche occupancy scores ( $\mathrm{z}$ values) on the first two PCA axes across both

152 seasons. We then used a PCA-env algorithm to evaluate the degree of overlap in occupied

153 niches along the PCA axes between species' breeding and non-breeding ranges, providing an

154 index of climate niche similarity (conservatism) between seasons (Broennimann et al. 2012).

155 To account for other variables that might influence population trends, we also

156 quantified habitat specialism and feeding guild for each species, as well as breeding and non-

157 breeding range size and mean latitude (constrained to the study area), and body mass. For 
158 habitat specialism, we used 'level 1' habitat classes in the IUCN Habitats Classification

159 Scheme (BirdLife International 2014). For simplicity, we used only classes listed as

160 important in the breeding season, and pooled habitat subcategories into a 6-level factor:

161 "forest", "shrubland", "farmland", "rocky/tundra", "wetland" and "general”, the latter

162 including species with multiple level 1 associations. We classified feeding guilds from

163 species accounts in Handbook of the Birds of the World Alive (www.hbw.com) using a 5-

164 level factor ("omnivore", "carnivore", "insectivore”, "granivore”, "herbivore”). Body mass is

165 included as it is a reliable proxy for a range of correlated life history characteristics

166 (Blummerstein \& Møller 2008; Gregory et al. 2009). We calculated mean migration distance

167 for each species as the great circle distance between the centroids of breeding and non-

168 breeding ranges. All mapping and analyses were carried out in R using packages 'sp', 'raster'

169 and 'FNN' (R Development Core Team 2008).

170

171 Statistical analysis

172 We modelled between-species differences in population trends using Generalized Linear

173 Mixed Models (GLMMs) with a family-level random effect to control for potential

174 phylogenetic non-independence of trends. To examine how our predictor variables influence

175 the probability of species decline across the whole survey period (1990-2012), we used a

176 binomial response variable where 'successes' were the number of census periods in which a

177 species was in decline, and 'failures' the number in which it was stable or increasing

178 (excluding from consideration any periods where trends were unknown or fluctuating). We

179 also repeated the analysis for each census period individually, again using a binomial

180 response $(1=$ declining, $0=$ stable or increasing $)$, excluding species for which trends were

181 unknown or fluctuating. 
182 We centred and standardized all predictor variables to ensure commonality of scales

183 (Schielzeth 2010). For variable pairs that were correlated after standardization (Pearson

$184 \mathrm{R}>0.5$ or $<-0.5$ ), we included whichever was deemed likely to have a more biologically

185 meaningful link to the response variable (see Table S3; Burnham \& Anderson 2002).

186 Substituting these excluded variables had little influence on the results (Table S4). Because

187 migratory strategy and migration distance are partially confounded (all residents have

188 distance 0 ), we used a binary dummy variable to differentiate partial migrants from other

189 species (i.e. $1=$ partial migrant, $0=$ fully migrant or resident). This allowed us to evaluate

190 whether partial migration explains variation in population trends above that explained by

191 migration distance alone.

We used an information-theoretic approach to account for model selection uncertainty and evaluate predictor effect sizes (Burnham and Anderson 2002). We compared all possible model combinations, ranking each model by its Akaike weight $\left(\mathrm{AIC}_{\mathrm{w}}\right)$ and using summed weights $\left(\Sigma \mathrm{AIC} \mathrm{w}_{\mathrm{w}}\right)$ as an index of relative importance for each term (Burnhan \& Anderson confidence set containing all top-ranked models summing to $0.95 \mathrm{AIC}_{\mathrm{w}}$. We used the 'zeroes' method for effect averaging (Grueber et al. 2011) which provides robust between-predictor comparisons. We inferred strong support for an effect whenever $95 \%$ confidence intervals for model-averaged effects excluded zero (Grueber et al. 2011). To assess overall model explanatory power, we calculated conditional and marginal $\mathrm{R}^{2}$ values for the global model using methods described in Nakagawa \& Schielzeth (2013).

For a subset of migratory species, we tested for relationships between the two migratory diversity metrics and advances in spring migration timing using univariate linear regressions. We obtained data on trends in mean Europe-wide spring arrival date from a published dataset for 89 European bird species (Møller et al. 2008, trends 1960-2006). We 
207 also repeated the full multi-model comparison for predictors of population trends within this

20889 species subset, including the mean trend in arrival date as an additional predictor variable.

209 This allowed us to compare the relative contributions of migratory diversity metrics and

210 arrival date trend towards explaining variation in population trends.

211 Results

212 Effects of migratory diversity on bird declines

213 Of the 340 species considered, $42 \%$ had positive migratory dispersion scores, $41 \%$ had

214 negative scores and 16\% were fully resident (i.e. dispersion $=0$ ). Model selection identified

215 migratory dispersion as an important predictor of decline probability (Tables $1 \&$ S5), with

216 higher dispersion being associated with lower probability of decline (Fig. 3). This effect was

217 consistent across both early and late census periods (Tables 1, S6 \& S7). Partial migration

218 was also identified as an important predictor of decline probability (Table $1 \&$ S5), with

219 partial migrants being less likely to decline on average than both full migrants and full

220 residents over the whole study period, and in particular over the early census period (Fig. 4,

221 Table S6). Both partial migration and migratory dispersion were consistently selected ahead

222 of migration distance as predictors of declines (Tables 1, S5-7), indicating that they explain

223 considerable variation in decline probabilities over and above that explained by between-

224 species differences in migration distance. Although partial migrants tended to have shorter

225 mean migration distances than full migrants (mean $\sim 2,050 \mathrm{~km} \pm 1,790 \mathrm{~s} . \mathrm{d}$. versus $\sim 4,700 \mathrm{~km}$

$226 \pm 2,010$ ), the partial migrant group contained many long-distance migrants (Fig. 5), with

227 almost half of sub-Saharan migrants (45.7\%) being classified as partial migrants.

228 For the subset of 86 species with available data on trends in mean spring arrival date, 229 arrival trends were strongly associated with favourable population trends (Table 1), echoing

230 previous findings (Møller et al. 2008). Partial migrants tended to show greater advancement 
231 in mean spring arrival date than full migrants $(\mathrm{F}=13.96, \mathrm{P}<0.001$; Fig. S2). The effect of

232 partial migration on decline probability became negligible when spring arrival trends were

233 included in the model (Table 1), suggesting that the link between partial migration and

234 population declines might be mediated by interspecific variation in spring arrival trends.

235 Migratory dispersion, by contrast, was not correlated with trends in spring arrival (Fig. S3),

236 and remained a strongly supported predictor of decline likelihood in this subset analysis

237 (Table 1), suggesting that the effect of dispersion acts independently of trends in spring

238 arrival timing.

239 Other predictors of population trends

240 Habitat specialism was an important predictor of population trends in all analyses,

241 with all specialist classes showing higher probabilities of decline than habitat generalists

242 (Table 1), with farmland specialists being particularly prone to decline (Table 1). Across the

243 whole study period, and in particular 1990-2000, there was strong support for an effect of

244 body mass on decline probability, with lighter species having higher decline probabilities

245 (Table 1). Little support was found for effects of guild, breeding latitude, climate niche

246 overlap or climate niche breadth in the full analyses (Table 1). Breeding latitude and niche

247 breadth did, however, receive some support in the subset analysis including data on spring

248 arrival trends, with decline probability tending to increase among species breeding at higher

249 latitudes, and species with higher winter climate niche breadth (Table 1).

250 The global model for the whole survey period explained $23.2 \%$ of variation in

251 probability of decline between species, of which $22.7 \%$ was attributable to fixed effects

252 (Table S8). Levels of variance explained were somewhat higher for models fitted to 1990-

2532000 trend data alone (33.4\%, Table S8) and somewhat lower for 2001-2012 trend data

$254(18.8 \%$, Table S8). 


\section{Discussion}

257 Our results demonstrate that migratory diversity is an important predictor of recent

258 population declines in migratory species. Species whose migratory movements allow them to 259 occupy larger areas in the non-breeding season, relative to their breeding ranges, were less

260 likely to decline than those whose populations are channelled into more restricted non-

261 breeding ranges. Partially migratory populations were also less likely to decline than either

262 full migrants or full residents. These patterns held true across both short and long-distance

263 migrants, indicating that migratory distance per se does not necessarily confer heightened

264 vulnerability to anthropogenic change. Rather, species with lower diversity in migratory

265 movements and destinations may be more vulnerable than those with more diverse ranges

266 and strategies. These interspecific differences help explain why some long-distance migrants

267 have maintained favourable population trends while others have severely declined (Vickery

268 et al. 2014).

269 Various mechanisms could drive the relationship between migratory diversity and the 270 probability of population decline. One possibility, as implied by migratory network models

271 (Fig. 2), is that diversity confers increased population-scale resilience to area-specific threats

272 in the non-breeding range (e.g. habitat degradation and hunting pressure). Our findings are in

273 broad accordance with model predictions that species with higher migratory dispersion may

274 increase population resilience (Fig. 2A-D), and that partially migratory species may be more

275 resilient than full migrants (Fig. 2E \& F) if negative impacts primarily occur in the non-

276 breeding range (Chapman et al. 2011b). Our results suggest that the dynamics of migratory

277 populations are indeed sensitive to the number, size and distribution of occupied non-

278 breeding sites, relative to the breeding range. While previous works have considered the 
279 consequences of spatial 'bottlenecks' arising as populations pass along migration corridors

280 (e.g. Weber et al. 1999; Berger et al. 2008; Sawyer et al. 2009), little attention has been paid

281 to the potential importance of equivalent 'bottlenecking' across non-breeding ranges. Our

282 results suggest that this plays an important role in determining population vulnerability to

283 environmental change.

Our findings also support the hypothesis that migratory diversity influences the capacity of species to respond to climate-driven shifts in resource phenology, as partial migrants showed greater rates of advancement in mean spring arrival date than full migrants

trends (Møller et al. 2008). The relationship between partial migration and arrival advancement could arise if partial migrants, as well as expressing between-individual variation in migratory behaviour itself, also express greater variability in the timing of migratory movements than full migrants. Such variation could facilitate shifts in migration timing at the population scale, if early-arriving individuals are more likely to encounter successful breeding conditions, and the resulting offspring also migrate earlier (Gill et al. 2014). Moreover, resident individuals within partially migratory populations are predisposed to match the timing of breeding with shifting resource abundance peaks (Chapman et al. 2011b). The same is true for fully-resident species, although interestingly our models suggest that full residents have higher decline probabilities on average than partial migrants (Fig. 4). This result implies that migration does not necessarily increase the vulnerability of species to environmental change relative to full residence, if a flexible range of migratory strategies is expressed.

The mechanisms that underpin the expression of different migratory strategies across populations remain poorly understood. In birds, a large component of migratory behaviour is genetically determined (Biebach 1983; Pulido \& Widmer 2005), implying that diversity 
304 might be tightly linked to the presence of heterogeneity in migratory gene expression across a

305 population (Biebach 1983; Kaitala 1993; Piersma 2011), which in turn may be influenced by

306 environmental or social cues. Within-individual plasticity in migratory behaviour can be

307 considerable, particularly in partial migrants where migratory behaviour may change within

308 an individual's lifetime (Nilsson et al. 2006; Olsson et al. 2006; Brodersen et al. 2008). It is

309 notable that partial migration is an extremely widespread strategy in European birds

310 (Chapman et al. 2011b), being found in $80 \%$ of the 55 avian families included in our study

311 (compared with full migration, found in $42 \%$ of families). In most cases, the degree of

312 population-scale migratory diversity expressed by a species is likely to depend on a complex

313 interplay between genetic heterogeneity and individual responses to social cues and local

314 environmental conditions. The relative strength of genetic versus social/environmental

315 determination may have important consequences for population resilience to environmental

316 change, as plasticity in response to external cues may facilitate more rapid population-scale

317 change (Marra et al. 2005).

318 Migratory diversity, whether arising through within-individual plasticity or between-

319 individual heterogeneity, might also increase the likelihood that new non-breeding areas are

320 colonized via the establishment of new migratory routes. Such colonisations are likely to be

321 important in determining the long-term persistence of migratory populations under changing

322 climates (La Sorte \& Thompson 2007). Moreover, the colonization of new non-breeding sites

323 could drive dynamic changes in migratory dispersion over time, with consequent implications

324 for population dynamics. Species with greater capacity to spread to new non-breeding sites

325 may therefore be more resilient to a range of environmental stressors, including both climate

326 change and habitat loss. Dynamic shifts in the non-breeding ranges of migratory species have

327 been demonstrated in a variety of taxa (see Robinson et al. 2009 for a review), but the

328 behavioural mechanisms by which these shifts occur remain poorly understood. 
329

330

331

332

333

334

335

336

337

338

339

340

341

342

343

344

345

346

347

348

349

350

351

352

353
Caveats

The effect of partial migration on decline probability was predominantly evident in the early census period, and partial migration was a weak predictor of declines in the late census period (Table 1). It is unclear why the positive effect of partial migration might have declined over time, but it appears to be associated with improving trends among full migrants in the second survey period, rather than an increase in the number of partial migrants declining. Over half of fully migratory species were in decline in 1990-2000 (50.4\%), but this fell to $35.7 \%$ in $2000-2012$, whereas the proportion of declining partial migrants remained fairly stable (33.1\% in $1990-2000$ versus $30.8 \%$ in $2000-2012)$. The factors driving this improvement in fortunes for fully migratory species are unclear, although this pattern could reflect the success of recent conservation interventions (Sanderson et al. 2015), given that migratory species are emphasized under Annex 1 of the EU Birds Directive (European Union 2009).

An important caveat associated with our results is that we use coarse species distribution maps that, although reflective of best current knowledge of range extents, do not capture fine-scale occupancy or abundance patterns within species' breeding, passage and non-breeding ranges (Rondinini et al. 2006). Our analyses do not account for the precise routes and staging areas used by populations during passage, as these are incompletely mapped for most species (Runge et al. 2014). As noted above, migratory populations can be highly vulnerable to threats occurring within migratory corridors or stop-over sites, if a high proportion of individuals pass through the same key areas (Weber et al. 1999; Berger et al. 2008). Such passage bottlenecks are perhaps most likely among species with low migratory dispersion, as well as those that migrate in large groups (e.g. waterbirds, many large mammals). Detailed mapping of the migration routes of declining migratory populations therefore remains an important conservation priority (Runge et al. 2014). 
354 By taking a single trend value for each species, our analyses assume that trends within

355 a given time window are constant across the whole European range. In fact, evidence

356 suggests that population trends of migratory species can be highly heterogeneous in space

357 (Villard \& Maurer 1996; Morrison et al. 2013). Future analyses accounting for this

358 heterogeneity, perhaps by using country-level rather than region-wide trend data, may offer

359 more nuanced insights into relationships between migratory behaviour and population

360 vulnerability. In particular, it may be possible to examine whether within-range population

361 trend heterogeneity correlates with spatial heterogeneity in migratory behaviour (e.g. by

362 comparing resident and migratory populations in partial migrant species). For the purposes of

363 this study, we assume that mean Europe-wide trend estimates provide a robust, if coarse,

364 index of interspecific variation in vulnerability to recent environmental change.

365 Conclusions

366 The power of map-based metrics of migratory diversity to explain population trends

367 suggests that they could be useful in evaluating species vulnerability to future anthropogenic

368 threats. Because our metrics use only coarse distributional data, they can be easily generated

369 using current estimates of species' seasonal distributions. Such metrics may be particularly

370 useful in regions where estimates of population trends are lacking, such that more detailed

371 assessments of species vulnerability are precluded. Migratory diversity metrics can provide

372 conservation-relevant information for almost any species where reasonably accurate

373 distributional data are available, even if those data are of low resolution.

374 Understanding how migratory diversity contributes to species vulnerability might also

375 help in the design and implementation of species-specific conservation management plans.

376 Species with low migratory dispersion, for example, might be expected to benefit from a

377 focus on conservation actions within the non-breeding distribution, such as the increased 
378 protection or restoration of habitats in key areas (Runge et al. 2015). The potential efficacy of

379 such actions for species with low migratory dispersion is exemplified by the positive

population trends of a handful of species (e.g. the pink-footed goose Anser brachyrhynchus

and barnacle goose Branta leucopsis) that have highly restricted non-breeding ranges, and yet

have maintained favourable population trends thanks to pro-active conservation measures

(MacMillan et al. 2004). It is important to note, however, that management should always be

informed by detailed examinations of the likely demographic drivers of population declines,

and where in the annual cycle these drivers are likely to operate. By incorporating migratory

diversity into future network-based analyses of migratory populations, it may be possible to

come to an improved understanding of these complex seasonal drivers.

\section{Acknowledgements}

\section{References}

1. Berger, J., Young, J.K. \& Berger, K.M. (2008) Protecting migration corridors: Challenges and optimism for Mongolian saiga. PLoS Biol., 6, e165.

2. Betini, G. S., Fitzpatrick, M. J. \& Norris, D. R. (2015). Experimental evidence for the effect of habitat loss on the dynamics of migratory networks. Ecol. Lett., 18, 526-534.

3. Biebach, H. (1983). Genetic determination of partial migration in the European robin (Erithacus rubecula). Auk, 3, 601-606. 
402 4. BirdLife International (2014) IUCN Red List for birds. Available at:

$403 \quad$ http://www.birdlife.org. Last accessed 30 May 2015.

404 5. BirdLife International (2015) European Red List of Birds. Available at:

405 http://www.birdlife.org/datazone/info/euroredlist. Last accessed 30 May 2015..

406 6. BirdLife International and NatureServe (2014) Bird species distribution maps of the

407 world. Version 4.0. Available at: http://www.birdlife.org/datazone/info/spcdownload.

$408 \quad$ Last accessed 30 May 2015.

409 7. Blummerstein \& Møller 2008

410 8. Both, C., Bouwhuis, S., Lessells, C. M., \& Visser, M. E. (2006). Climate change and

411 population declines in a long-distance migratory bird. Nature, 441, 81-83.

412 9. Brodersen, J., Nilsson, P. A., Hansson, L. A., Skov, C., \& Brönmark, C. (2008).

413 Condition-dependent individual decision-making determines cyprinid partial

414 migration. Ecology, 89, 1195-1200.

415 10. Broennimann, O., et al. (2012). Measuring ecological niche overlap from occurrence

416 and spatial environmental data. Glob. Ecol. Biogeog., 21, 481-497.

417 11. Burnham, K.P. \& Anderson, D.R. (2002) Model selection and multi-model inference:

418 a practical information-theoretic approach. Springer, New York.

419 12. Chapman, B.B., et al. (2011a). To boldly go: individual differences in boldness

420 influence migratory tendency. Ecol. Lett., 14, 871-876.

421 13. Chapman, B.B., Brönmark, C., Nilsson, J.Å., \& Hansson, L.A. (2011b). The ecology

422 and evolution of partial migration. Oikos, 120, 1764-1775.

423 14. European Union. (2009) Directive 2009/147/EC of the European parliament and of

424 the council. http://eur-lex.europa.eu/legal-

425 content/EN/TXT/PDF/?uri=CELEX:32009L0147\&from=EN (visited Nov. 1, 2015). 
426 15. Gill, J.A. et al. (2014) Why is timing of bird migration advancing when individuals

427 are not? Proc. Royal Soc. B, 281, 20132161

428 16. Gregory, R.D., et al. (2009). An indicator of the impact of climatic change on

$429 \quad$ European bird populations. PloS one, 4, e4678.

430 17. Grueber, C.E., Nakagawa, S., Laws, R.J., \& Jamieson, I. G. (2011). Multimodel

431 inference in ecology and evolution: challenges and solutions. J. Evol. Biol., 24, 699-

432711.

433 18. Hijmans, R.J., S.E. Cameron, J.L. Parra, P.G. Jones \& A. Jarvis, (2005). Very high

434 resolution interpolated climate surfaces for global land areas. Int. J. Climatol. 25, $435 \quad 1965-1978$.

436 19. Kaitala, A., Kaitala, V., \& Lundberg, P. (1993). A theory of partial migration. Am.

437 Nat., 142, 59-81.

438 20. La Sorte, F. A. L., \& Thompson, F. R. T. III (2007). Poleward shifts in winter ranges 439 of North American birds. Ecology, 88, 1803-1812.

440 21. López-López, P., García Ripollés, C., \& Urios Moliner, V. (2014). Individual

441 repeatability in timing and spatial flexibility of migration routes of trans-Saharan 442 migratory raptors. Curr. Zool., 60, 642-652.

443 22. Lundberg, P. (1988). The evolution of partial migration in birds. Trends Ecol. Evol., $444 \quad 3,172-175$.

445 23. MacMillan, D., Hanley, N., \& Daw, M. (2004). Costs and benefits of wild goose 446 conservation in Scotland. Biol. Conserv., 119, 475-485.

447 24. Marra, P.P., Francis, C.M., Mulhivill, R.S. \& Moore, F.R. (2005). The influence of 448 climate on the timing and rate of spring bird migration. Oecologia, 142, 307-315. 
449 25. Morrison, C.A., Robinson, R.A., Clark, J.A., Risely, K., \& Gill, J.A. (2013). Recent

450 population declines in Afro-Palaearctic migratory birds: the influence of breeding and

451 non-breeding seasons. Divers. Distrib., 19, 1051-1058.

452 26. Møller, A.P., Rubolini, D., \& Lehikoinen, E. (2008). Populations of migratory bird

453 species that did not show a phenological response to climate change are declining.

454 Proc. Nat. Acad. Sci., 105, 16195-16200.

455 27. Nakagawa, S. \& Schielzeth, H. (2013). A general and simple method for obtaining $\mathrm{R}^{2}$

456 from generalized linear mixed-effects models. Methods Ecol. Evol., 4, 133-142.

457 28. Nilsson, A.L.K., Lindström, Å., Jonzén, N., Nilsson, S.G. \& Karlsson, L. (2006). The

458 effect of climate change on partial migration - the blue tit paradox. Glob. Change

459 Biol., 12, 2014-2022.

460 29. Nilsson, A.L.K., Alerstam, T., \& Nilsson, J. Å. (2008). Diffuse, short and slow

461 migration among blue tits. J. Ornith., 149, 365-373.

462 30. Olsson, I. C., Greenberg, L.A., Bergman, E., \& Wysujack, K. (2006).

463 Environmentally induced migration: the importance of food. Ecol. Lett., 9, 645-651.

464 31. Piersma, T. (2011). Flyway evolution is too fast to be explained by the modern

465 synthesis: proposals for an 'extended' evolutionary research agenda. J. Ornith., 152,

$466 \quad 151-159$

467 32. Pulido, F. \& Widmer, M. (2005). Are long-distance migrants constrained in their

468 evolutionary response to environmental change? Causes of variation in the timing

469 autumn migration in a blackcap (Sylvia atricapilla) and two garden warbler (Sylvia

470 borin) populations. Ann. N. York Acad. Sci., 1046. 228-241.

471 33. R Development Core Team (2008). R: A language and environment for statistical

472 computing. R Foundation for Statistical Computing. Available at: http://www.R-

$473 \quad$ project.org. Last accessed 30 May 2015. 
34. Robbins, C. S., Sauer, J. R., Greenberg, R. S., \& Droege, S. (1989). Population declines in North American birds that migrate to the Neotropics. Proc. Nat. Acad. Sci., 86, 7658-7662.

35. Robinson, R.A., et al. (2009). Travelling through a warming world: climate change and migratory species. Endang. Species Res., 7, 87-99.

36. Rondinini, C., Wilson, K. A., Boitani, L., Grantham, H., \& Possingham, H. P. (2006). Tradeoffs of different types of species occurrence data for use in systematic conservation planning. Ecol Lett., 9, 1136-1145.

37. Runge, C. A., Martin, T. G., Possingham, H. P., Willis, S. G., \& Fuller, R. A. (2014). Conserving mobile species. Frontiers Evol. Envir., 12, 395-402.

38. Runge, C. A., Watson, J. E. M., Butchart, S. H. M., Hanson, J. O., Possingham, H. P. \& Fuller, R. A. (in press) Protected area coverage and migratory birds. Science,

39. Sanderson, F. J., Donald, P. F., Pain, D. J., Burfield, I. J., \& Van Bommel, F. P. (2006). Long-term population declines in Afro-Palearctic migrant birds. Biol. Conserv., 131, 93-105.

40. Sanderson, F.J., Pople, R.G., Ieronymidou, C., Burfield, I.J., Gregory, R.D., Willis, S.G., Howard, C., Stephens, P.D., Beresford, A.E. \& Donald, P.F. (2015). Assessing the Performance of EU Nature Legislation in Protecting Target Bird Species in an Era of Climate Change. Conserv. Lett.

41. Sawyer, H., Kauffman, M. J., Nielson, R. M., \& Horne, J. S. (2009). Identifying and prioritizing ungulate migration routes for landscape-level conservation. Ecol. Applications, 19, 2016-2025.

42. Schielzeth, H. (2010) Simple means to improve the interpretability of regression coefficients. Methods Ecol. Evol., 1, 103-113. 
498

499

500

501

502

503

504

505

506

507

508

509

510

511

512

513

514

515

516

517

518

519

43. Sutherland, W. J., \& Dolman, P. M. (1994). Combining behaviour and population dynamics with applications for predicting consequences of habitat loss Proc. Royal Soc. $B, 255,133-138$.

44. Taylor, C.M. \& Norris, D.R. (2010). Population dynamics in migratory networks. Theor. Ecol., 3, 65-73.

45. Thaxter, C.B., Joys, A.C., Gregory, R.D., Baillie, S.R., \& Noble, D.G. (2010). Hypotheses to explain patterns of population change among breeding bird species in England. Biol. Conserv., 143, 2006-2019.

46. Vardanis, Y., Klaassen, R. H., Strandberg, R., \& Alerstam, T. (2011). Individuality in bird migration: routes and timing. Biol. Lett., rsbl20101180.

47. Vickery, J.A., Ewing, S.R., Smith, K.W., Pain, D.J., Bairlein, F., Škorpilová, J., \& Gregory, R.D. (2014). The decline of Afro-Palaearctic migrants and an assessment of potential causes. Ibis, 156, 1-22.

48. Villard, M.A., \& Maurer, B.A. (1996). Geostatistics as a tool for examining hypothesized declines in migratory songbirds. Ecology, 77, 59-68.

49. Weber, T. P., Houston, A. I., \& Ens, B. J. (1999). Consequences of habitat loss at migratory stopover sites: a theoretical investigation. J. Avian Biol., 30, 416-426.

50. Webster, M. S., Marra, P. P., Haig, S. M., Bensch, S., \& Holmes, R. T. (2002). Links between worlds: unraveling migratory connectivity. Trends Ecol. Evol., 17, 76-83.

51. Wilcove, D.S. \& Wikelski, M. (2008) Going, going, gone: Is animal migration disappearing? PLoS Biol., 6, e188 


\section{Supplementary material \\ 521 Additional Supporting Information may be downloaded via the online version of this article \\ 522 at Wiley Online Library (www.ecologyletters.com).}


Table 1 Performance of candidate variables in explaining the probability of population decline. Effect sizes reflect model-averaged parameter estimates $\hat{\beta}$ and bootstrap 95\% confidence intervals. Results are shown for model selection applied to the full dataset (340 species) across the whole study period (1990-2012), plus each census period individually. We also re-ran the analysis for a subset of 89 species with data on trends in mean Europe-wide spring arrival date. Model averaged parameter estimates with confidence intervals that do not overlap zero are shown in bold.

\begin{tabular}{|c|c|c|c|c|c|c|c|c|}
\hline Dataset: & $\begin{array}{c}\text { Whole period } \\
1990-2012\end{array}$ & & $\begin{array}{c}\text { Early period } \\
1990-2000\end{array}$ & & $\begin{array}{l}\text { Late period } \\
2001-2012\end{array}$ & & $\begin{array}{c}\text { Spring arrival } \\
\text { dataset }(\mathrm{n}=89) \\
1990-2012\end{array}$ & \\
\hline Variable: & $\widehat{\beta}(\mathrm{LCl}, \mathrm{UCl})$ & $\Sigma$ EAICc & $\widehat{\beta}(\mathrm{LCl}, \mathrm{UCl})$ & $\Sigma$ IAICc & $\widehat{\beta}(\mathrm{LCl}, \mathrm{UCl})$ & $\Sigma$ EAICc & $\widehat{\beta}(\mathrm{LCI}, \mathrm{UCl})$ & $\Sigma$ AICc \\
\hline Partial migration & $-0.53(-0.96,-0.11)$ & 0.98 & $-1.11(-1.74,-0.47)$ & 1.00 & $0.04(-0.45,0.46)$ & 0.21 & $-0.01(-1.27,1.26)$ & 0.22 \\
\hline Migratory dispersion & $-0.27(-0.49,-0.05)$ & 0.95 & $-0.27(-0.67,-0.04)$ & 0.90 & $-0.20(-0.45,-0.03)$ & 0.83 & $-0.65(-1.26,-0.05)$ & 0.84 \\
\hline Migration distance & $0.22(-0.04,0.48)$ & 0.61 & $0.22(0.02,0.76)$ & 0.81 & $0.07(-0.21,0.34)$ & 0.24 & $0.24(-0.65,0.58)$ & 0.22 \\
\hline Climate niche overlap & $0.10(-0.13,0.33)$ & 0.32 & $0.10(-0.16,0.51)$ & 0.36 & $0.04(-0.19,0.26)$ & 0.22 & $-0.03(-0.66,0.59)$ & 0.20 \\
\hline Climate niche breadth & $0.21(-0.01,0.42)$ & 0.72 & $0.21(-0.02,0.60)$ & 0.68 & $0.14(-0.10,0.37)$ & 0.31 & $0.66(0.12,1.19)$ & 0.87 \\
\hline Mean breeding latitude & $-0.11(-0.35,0.12)$ & 0.33 & $-0.11(-0.67,0.03)$ & 0.66 & $0.20(-0.03,0.45)$ & 0.47 & $0.66(0.04,1.27)$ & 0.65 \\
\hline Body mass & $-0.33(-0.61,-0.06)$ & 0.96 & $-0.33(-1.03,-0.02)$ & 0.95 & $-0.21(-0.49,0.07)$ & 0.45 & $-0.98(-2.82,0.86)$ & 0.63 \\
\hline Habitat *: & & 1.00 & & 0.97 & & 1.00 & & 1.00 \\
\hline Farmland & $2.17(1.28,3.07)$ & - & $2.17(0.73,3.26)$ & - & $2.35(1.30,3.41)$ & - & $6.13(3.03,9.23)$ & - \\
\hline Forest & $0.59(-0.30,0.48)$ & - & $0.59(-0.99,1.50)$ & - & $0.84(-0.21,1.89)$ & - & $2.09(-0.46,4.65)$ & - \\
\hline Shrubland & $1.20(0.25,2.16)$ & - & $1.20(-0.68,2.10)$ & - & $1.55(0.44,2.67)$ & - & $1.62(-1.07,4.31)$ & - \\
\hline Rocky & $1.03(0.04,2.02)$ & - & $1.03(-0.93,1.84)$ & - & $1.62(0.46,2.78)$ & - & $2.60(-0.26,5.40)$ & - \\
\hline Wetland & $1.24(0.37,2.13)$ & - & $1.24(-0.22,2.25)$ & - & $1.65(0.60,2.69)$ & - & $2.93(0.49,5.37)$ & - \\
\hline Guild *: & & 0.06 & & 0.01 & & 0.34 & & 0.02 \\
\hline Omnivore & $0.56(-0.12,1.25)$ & - & $0.03(-0.81,1.09)$ & - & $0.93(-0.17,1.69)$ & - & $-1.34(-3.77,1.10)$ & - \\
\hline Insectivore & $0.07(-0.62,0.75)$ & - & $0.05(-1.19,0.71)$ & - & $0.36(-0.35,1.07)$ & - & $-0.21(-2.50,2.07)$ & - \\
\hline Granivore & $0.48(-0.38,1.34)$ & - & $0.01(-1.24,1.16)$ & - & $1.05(-0.16,1.94)$ & - & $0.04(-2.73,2.80)$ & - \\
\hline Herbivore & $0.15(-0.90,1.20)$ & - & $0.05(-1.18,1.86)$ & - & $-0.16(-1.29,0.98)$ & - & $1.45(-1.50,4.40)$ & - \\
\hline Spring arrival trend & $\mathrm{n} / \mathrm{a}$ & $\mathrm{n} / \mathrm{a}$ & $\mathrm{n} / \mathrm{a}$ & $\mathrm{n} / \mathrm{a}$ & $\mathrm{n} / \mathrm{a}$ & $\mathrm{n} / \mathrm{a}$ & $0.78(0.14,1.43)$ & 0.86 \\
\hline
\end{tabular}

*For categorical variables, parameter estimates are given relative to a reference category ('general' for habitat, 'carnivore' for guild 
Figure 1 Examples of within-species migratory diversity. Partial migrants (A \& B) are migratory species that occur in some parts of their range all year; full migrants (C \& D), by contrast, vacate their breeding ranges entirely during the non-breeding period. Migratory dispersion reflects the extent to which species occupy larger or smaller non-breeding ranges relative to the breeding period. Examples show species with relatively low (A \& C) and high (B \& D) levels of dispersion.

Figure 2 Hypothetical population networks with varying migratory diversity. Networks consist of 'nodes' (squares) representing equally-sized areas occupied in the breeding (green) or non-breeding season (blue), connected by 'edges' reflecting migration routes (lines, width indicates number of individuals using each route). Numbers show the model-derived equilibrium population sizes at each node in each scenario (details given in Appendix S1). Populations with low migratory dispersion (A) show marked declines following an $80 \%$ loss of habitat at one non-breeding node $(\mathrm{B}$, grey=impacted node). For an equivalent population with higher migratory dispersion (C), the same level of habitat loss has a markedly lower impact (D). For a partially migratory population, where a proportion of individuals at one breeding node are resident $(\mathrm{E}$, purple $=$ partially migratory node $)$, the impact is further reduced $(\mathrm{F})$.

Figure 3 Population trends in relation to migratory dispersion. Lines show the modelaveraged slope and bootstrap 95\% confidence intervals from a model set predicting the declines over the whole study period (1990-2012). Bars show the proportion of species that were stable or increasing (blue lower bars) or declining (orange, inverted upper bars) in relation to migratory dispersion (binned data). Tick marks above and below bars show the locations of individual data points on the $\mathrm{x}$ axis (lower $=$ stable or increasing species, upper $=$ declining species). 
Figure 4 Population trends in relation to migratory strategy. Points and error bars show mean model-averaged predictions and bootstrap 95\% confidence intervals for each strategy, from models explaining the probability of decline across the whole survey period, and to census period individually. Bars show the proportion of species in each class that were stable or increasing (blue, lower bars) or declining (orange, inverted upper bars) in any given survey period.

Figure 5 European bird declines in relation to migration strategies. Lines show great circle routes linking breeding and non-breeding range centroids for all non-pelagic migratory species, color-coded according to population trend (orange $=$ decreasing in one or more survey period, blue $=$ stable or increasing in both survey periods). Species are classed as either partial migrants (A) or full migrants (B) from the presence or absence of seasonal range overlap. Histograms show the frequency distribution of mean migration distance for partial (C) and full migrants (D); numbers above bars show the proportion of species in decline within each distance bin. 

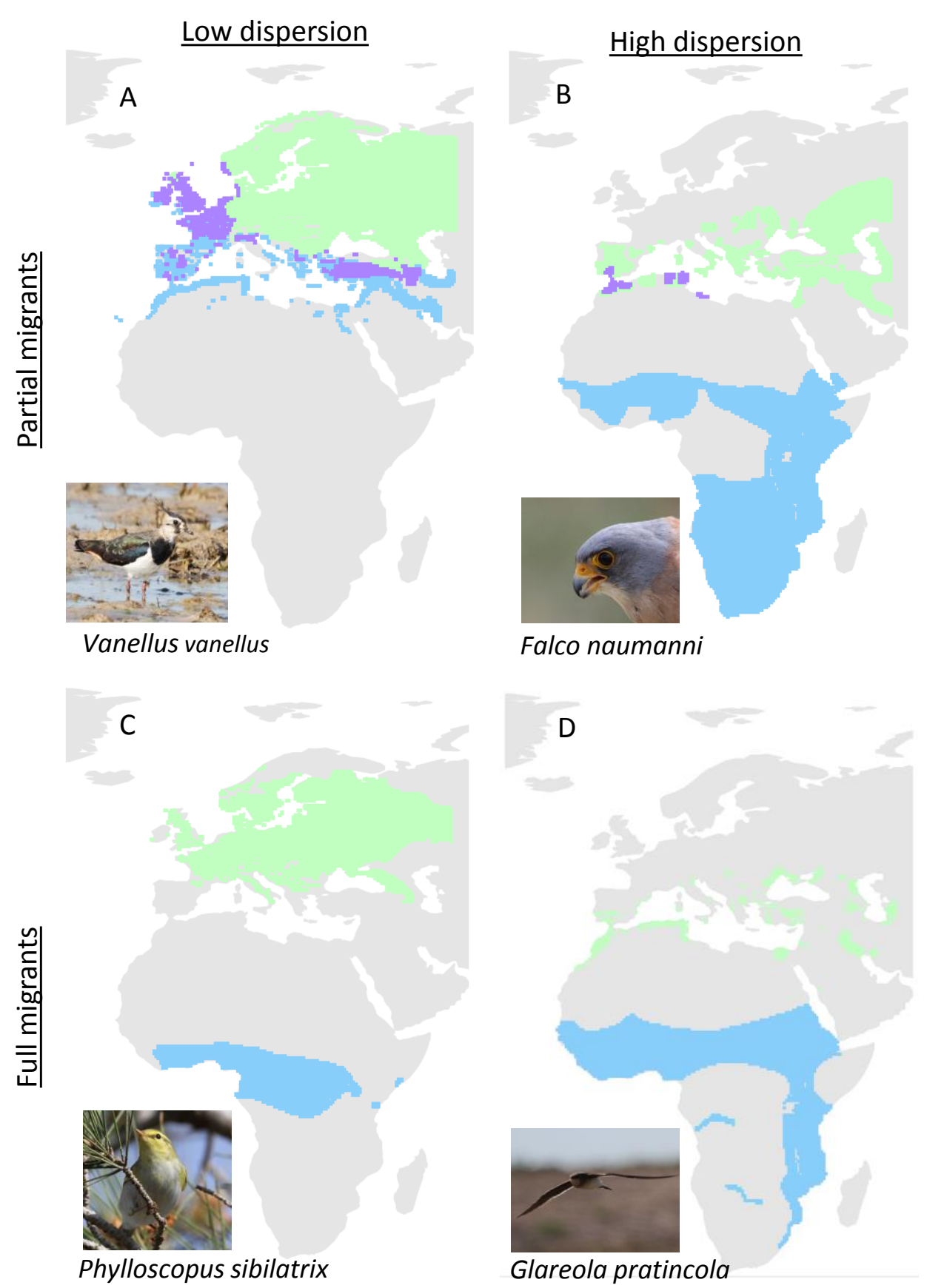

Key: $\quad=$ summer only $\quad=$ winter only $\quad \quad=$ summer $\&$ winter 
A

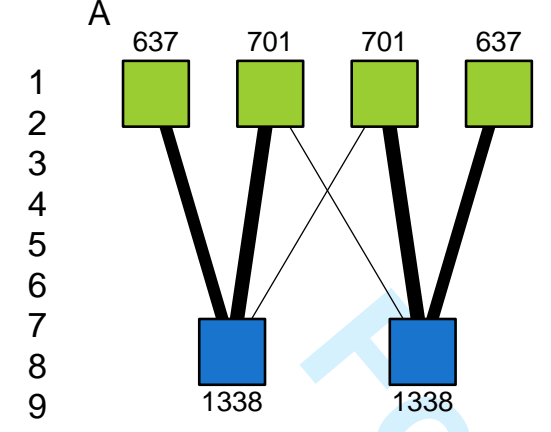

10

11

12

13

14

15

16

17

18

19

20

21

22

23

24

25

26

27

28

29

30

3

3

33

34

35

36

37

38

39

40

C

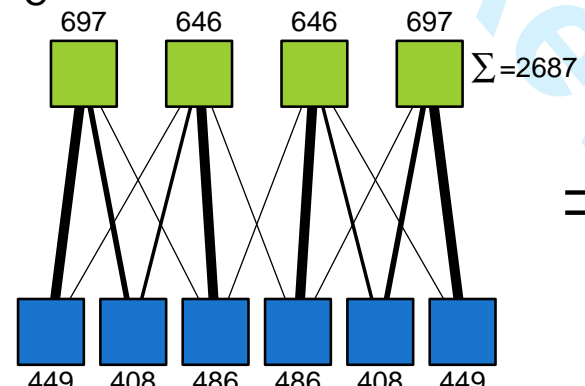

$\begin{array}{llllllll}449 & 408 & 486 & 486 & 408 & 449\end{array}$

(2)

7

9

$E$

620

$\begin{array}{llll}620 & 701 \quad 649 \quad 699\end{array}$

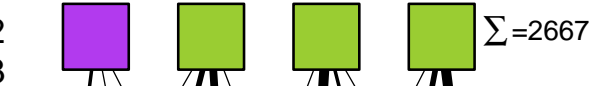

41

42
B
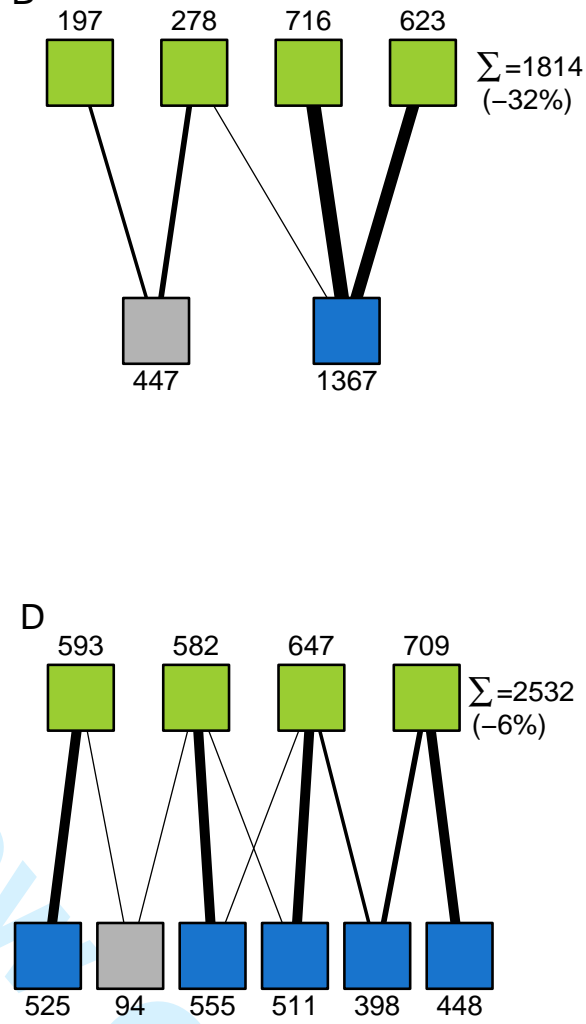

F

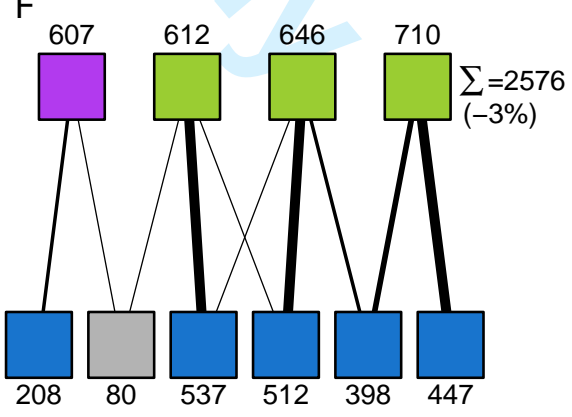




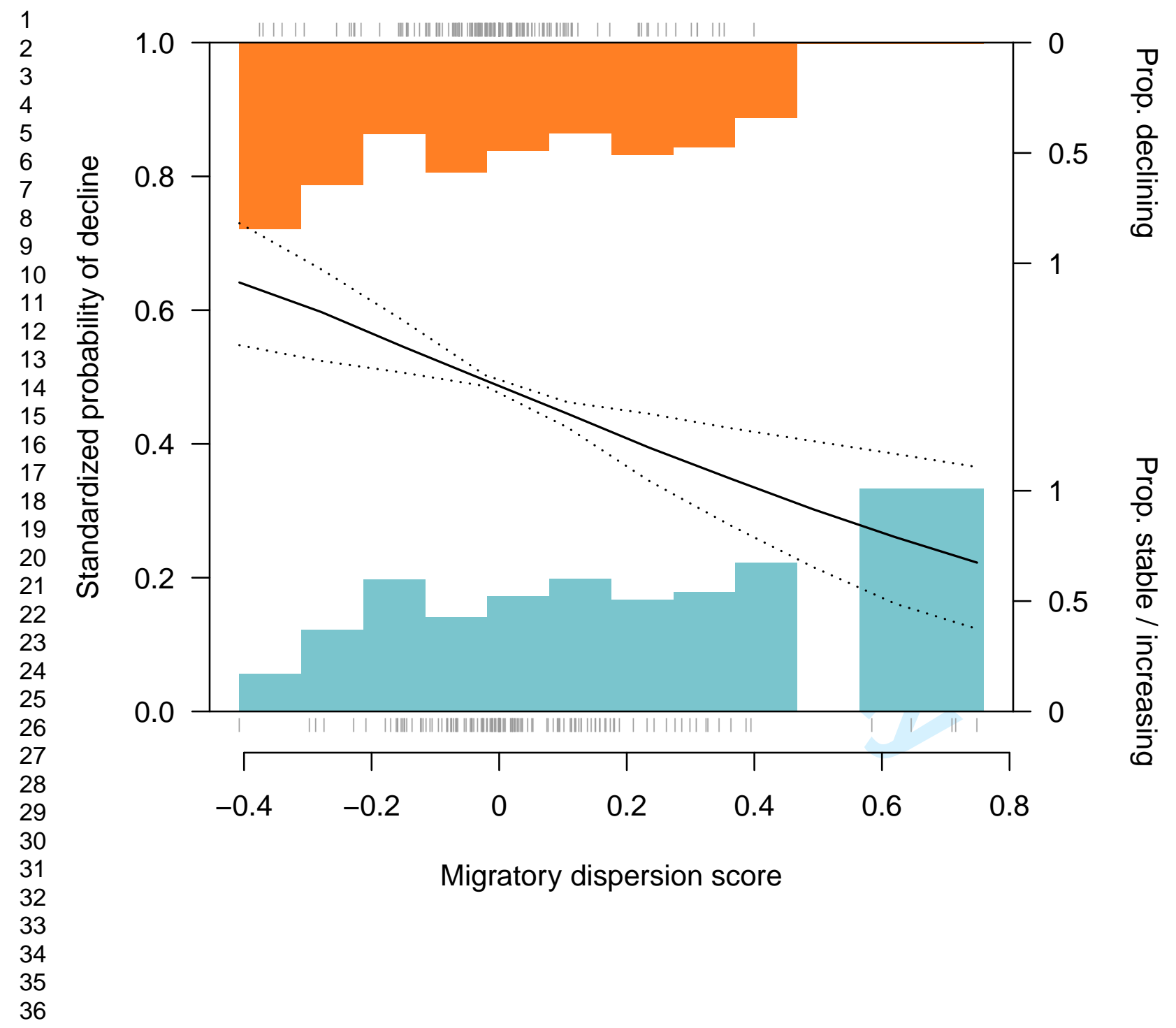


Ecology Letters

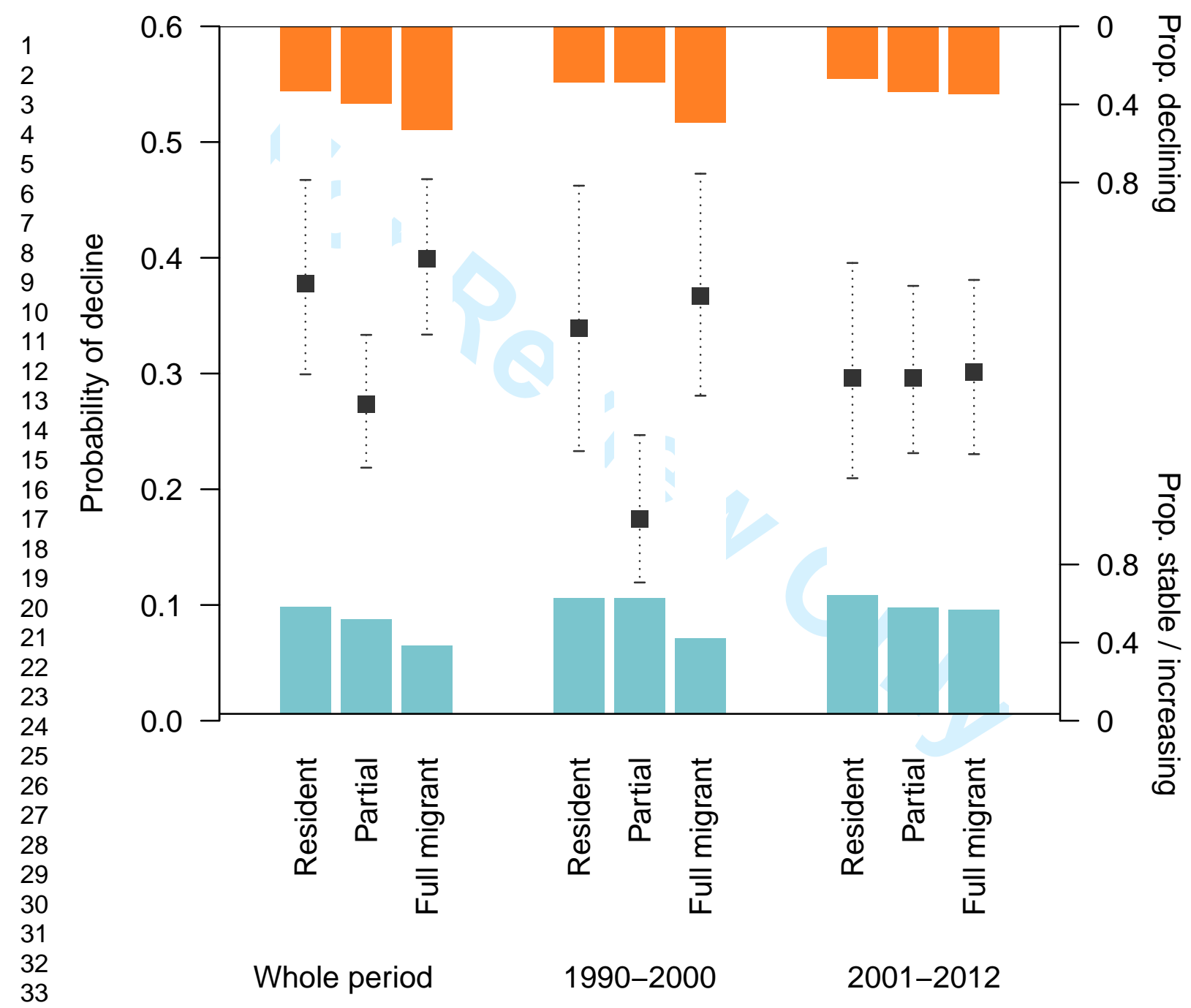




\section{A Partial migrants}

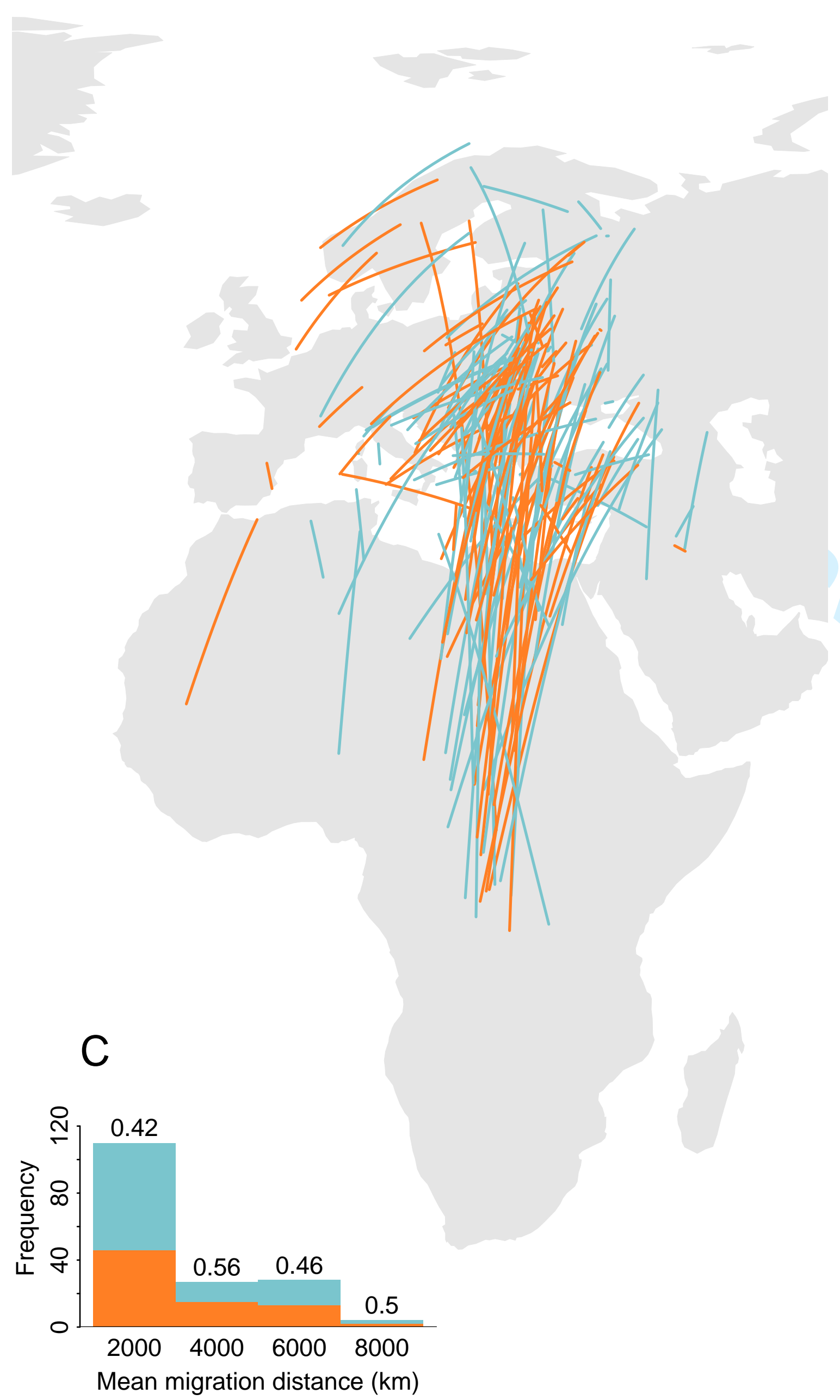

B Full migrants

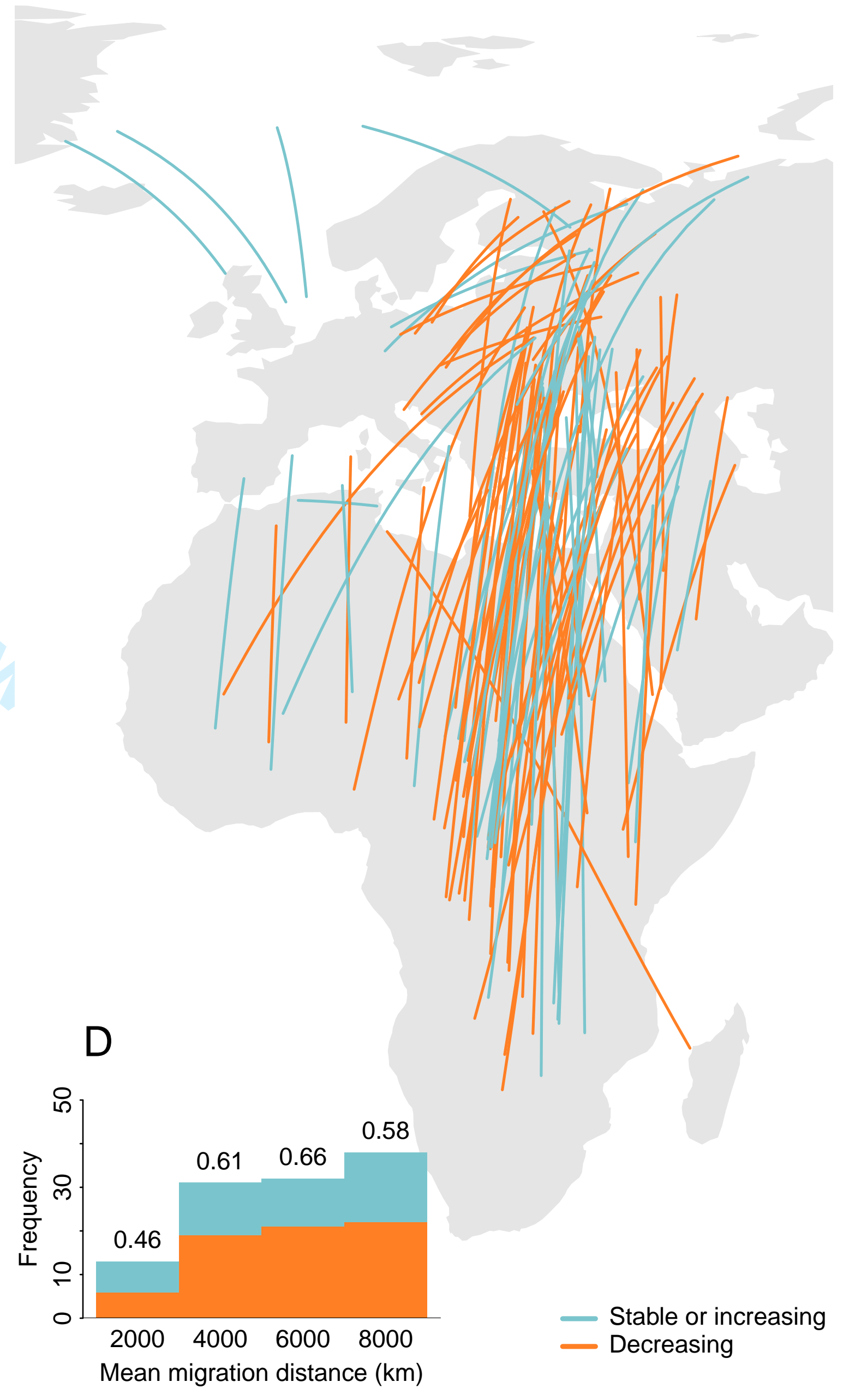

